\title{
THE UTILITY OF ISOLATION HOSPITALS IN DIMINISHING THE SPREAD OF SCARLET FEVER.
}

\author{
CONSIDERED FROM AN EPIDEMIOLOGICAL STANDPOINT.
}

\author{
By ARTHUR NEWSHOLME, M.D.
}

Medical Officer of Health for Brighton.

THERE have not been wanting those who have alleged that isolation hospitals have failed to fulfil the object for which they were erected, inasmuch as scarlet fever has during the last few years been prevalent to an exceptional extent. Those who argue thus, are in favour of diminishing expenditure on the erection and maintenance of isolation hospitals, and consider that we must trust to "improved sanitation" for diminishing and possibly in the end annihilating infectious diseases.

The problem deserves consideration, especially as it must be admitted in limine, that the enforcement of hospital isolation has not been so successful in diminishing the prevalence of scarlet fever, as might have been anticipated on $\dot{a}$ priori grounds. I have purposely chosen to consider the problem in relation to scarlet fever, as the case that can be made out in favour of hospital isolation for this disease, is very much weaker than for the same measure in diphtheria, enteric fever, and small-pox. The immense good effected both preventively and therapeutically by the hospital treatment of these three diseases is beyond dispute.

What, however, are the facts as regards scarlet fever? These may be gathered from a study of Fig. 1. This plate shows that in former times there were immense oscillations in the death-rate from scarlet fever, and that these have now become so insignificant as to be almost inappreciable on a diagram drawn to the above scale. Thus in 1861 the death-rate from scarlet fever fell to 451 , and in 1863 it had risen to 1478 per million of population. In 1866 it had fallen again 
146

The Utility of Isolation Hospitals

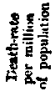

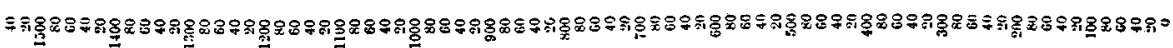

s.

(……
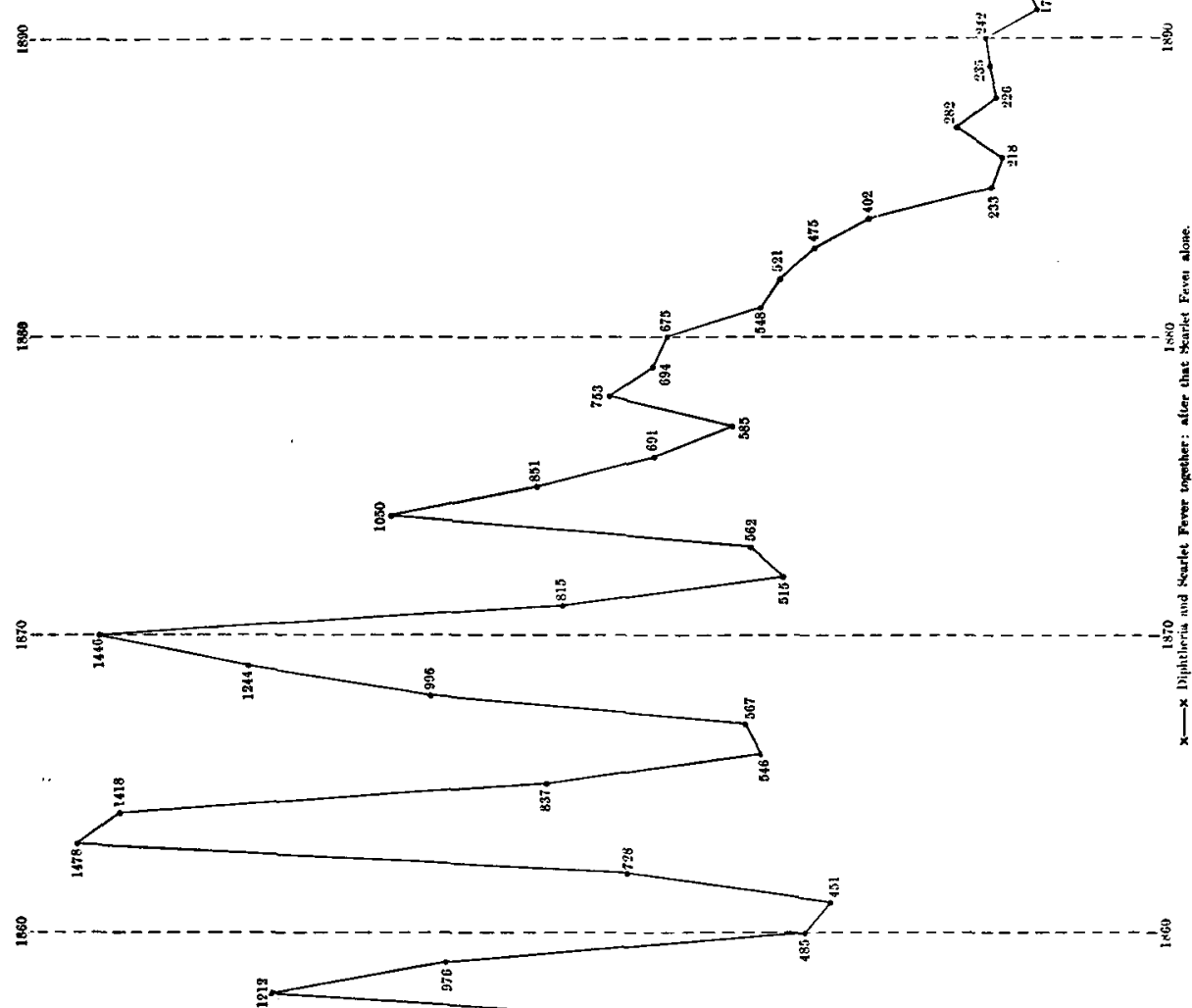
to 546 and in 1870 had risen to 1446 per million. Compare this state of matters with the subsequent course of the scarlatinal curve. In $1874-5$ a rise to a smaller extent occurred and again in 1878 a still smaller rise. Then a steady fall until 1887, when a trifling rise occurred, the next rise appearing in 1893 , when the death-rate only reached 235 per million. It is clear therefore that if death-rates are to be taken as a guide, the scarlatinal returns show a strong case for the continued use of the present preventive measures, among which hospital isolation and disinfection claim an important part. The Infectious Disease (Notification) Act became law in 1889. It cannot be claimed, however, that hospital isolation dates from this year. The Act was, except in London, an adoptive Act, and local authorities have been very slow to adopt it. The present year (1900) is the first in which a similar Act has been made generally compulsory. On the contrary, many districts had local compulsory notification for years before 1889 ; isolation hospitals throughout the country were becoming more numerous year by year, and the public were being educated as to the necessity for isolation and disinfection, to a rapidly increasing extent from the eighth decade of the 19th century onwards to the present date.

It is alleged, however, that the number of cases of scarlet fever has not, even though the total number of deaths has declined. Thus in Bradford the number of cases notified in 1881 (under a local Notification Act) was 23, in 1899 it was $9 \cdot 7$ per 1000 of population; in Nottingham under a similar Act 23 cases were notified in 1883 and 10.4 per 1000 of population in 1899 . (In this latter town 48 per cent. of the total cases were removed to the isolation hospital in 1899, while in 189871 per cent. of the total 931 cases were thus removed.) On the strength of figures like the above it has been asserted that notification and isolation of patients in hospitals are useless, and that they may be an impediment to true sanitary progress by diverting attention from sanitary reform.

It cannot be seriously argued that notification per se can increase the amount of infection. Nor can the conclusion be seriously resisted that notification, by increasing the sources of information, and making it more complete than it would otherwise be, must aid in the prevention of the notified disease, assuming that the right measures of prevention are taken. The question is, are removal of patients to hospital and disinfection of homes after removal the right measures? It has been contended that they are not; and that the increased number of cases of 
scarlet fever since notification came into force supports this contention. Such an increase when a sufficiently long series of years is taken, has not however been proved, and is in fact highly improbable. There can be no exact comparison of cases in pre- and post-notification years. Since notification began there has been a steady diminution in the severity of scarlet fever, as evidenced by its case-fatality. Hence it is impracticable to apply present fatality-rates to old statistics of mortality, and argue as to decrease or increase of total number of cases of scarlet fever. Scarlet fever differs from enteric fever and to a less extent from measles in its very great variations of virulence. At one time in the words of Sydenham hoc morbi nomen, vix enim altius assurgit; while only a few years later it may again assume intense virulence. The causes of these variations of virulence are imperfectly known. I am not prepared to state that the treatment in recent years of so large a proportion of the total number of cases in isolation hospitals has been the chief determining cause of the change; but that it has helped in producing it, is highly probable. Hence it is a perfectly gratuitous assumption to suppose that since hospital isolation has been largely practised, the number of cases of scarlet fever has increased. Notification has brought them into more prominent public attention, but the statement that they are more numerous than before notification began, is an unproved and unwarrantable assertion. All that we know with certainty is that the number of deaths from scarlet fever has declined to a most remarkable extent: of the number of cases we can in the majority of districts only speak since 1890 , too short a period to form valid conclusions as to any method of prevention. Even in towns in which notification returns are available for two decades, conclusions as to the efficacy of preventive measures based on the number of cases in successive years must necessarily be fallacious. We cannot secure the essential condition of " ceteris paribus."

Light has been thrown on the character of these other conditions by the independent observations of Gresswell and Longstaff ${ }^{1}$ who showed that there was an inverse relationship between the amount of scarlet fever and the annual rainfall; Gresswell further suggesting that " not only the rainfall of the year, but also that of prior years, has influence on scarlatina." Without pursuing this point in detail, it may be briefly stated that all the epidemic peaks shown in Fig. 1 occur in exceptionally dry periods; wet years being always years of little scarlet fever. The

1 Trans. Epidem. Soc. 1880, p. 429.

2 A Contribution to the Natural History of Scarlatina (Clar. Press, 1890), p. 192. 
years 1887, 1893, and 1899 were again years of exceptional drought; and yet how puny are the epidemic peaks of these as compared with those of earlier years! No hygienist has claimed that isolation and disinfection can entirely prevent the occurrence of these epidemic peaks, which are due to cyclical causes beyond our control. All that isolation and disinfection can do in the prevention of scarlet fever is to minimise the possibilities of infection and keep the epidemic peaks down below the height which they would attain in the absence of these measures. A glance at Fig. 1 almost irresistibly suggests that great success has been attained in this direction. The last fifteen years have been almost unexampled for the large proportion of dry years that have occurred, and especially the years from 1892 onwards, as may be seen from the following table.

\section{Rainfali at Greenwich.}

\begin{tabular}{|c|c|c|c|}
\hline Year & $\begin{array}{c}\text { Rainfall in } \\
\text { inches }\end{array}$ & $\begin{array}{c}\text { Departure from } \\
\text { average of } \\
50 \text { years }\end{array}$ & $\begin{array}{c}\text { Accumulated } \\
\text { deflciency }\end{array}$ \\
\hline 1887 & $19 \cdot 9$ & $-4 \cdot 2$ & $4 \cdot 2$ \\
1888 & $27 \cdot 5$ & $+3 \cdot 4$ & $0 \cdot 8$ \\
1889 & $23 \cdot 3$ & $-0 \cdot 8$ & $1 \cdot 6$ \\
1890 & $21 \cdot 9$ & $-2 \cdot 2$ & $3 \cdot 8$ \\
1891 & $25 \cdot 1$ & $+1 \cdot 0$ & $2 \cdot 8$ \\
1892 & $22 \cdot 3$ & $-1 \cdot 8$ & $4 \cdot 6$ \\
1893 & $20 \cdot 1$ & $-4 \cdot 0$ & $8 \cdot 6$ \\
1894 & $26 \cdot 9$ & $+2 \cdot 8$ & $5 \cdot 8$ \\
1895 & $19 \cdot 7$ & $-4 \cdot 4$ & $10 \cdot 2$ \\
1896 & $22 \cdot 4$ & $-1 \cdot 7$ & $11 \cdot 9$ \\
1897 & $22 \cdot 1$ & $-2 \cdot 0$ & $13 \cdot 9$ \\
1898 & $18 \cdot 9$ & $-5 \cdot 3$ & $19 \cdot 2$ \\
1899 & $22 \cdot 3$ & $-1 \cdot 8$ & $21 \cdot 0$ \\
\hline
\end{tabular}

And yet notwithstanding the fact that the elements have been fighting against them, preventive measures, among which hospital isolation holds an important place, have been associated with the remarkable and almost uninterrupted decline in the death-rate from scarlet fever shown in Fig. 1.

The limitations as well as the extent of the utility of preventive measures against scarlet fever need to be recognised. Even when all practicable preventive measures have been adopted,- -and that point is still very distant,-there will, I believe, remain a residuum of infection, the operation of which with our present limited knowledge we cannot prevent, owing to the occurrence of "epidemic influences," beyond our control. The state of matters may be illustrated diagrammatically. 


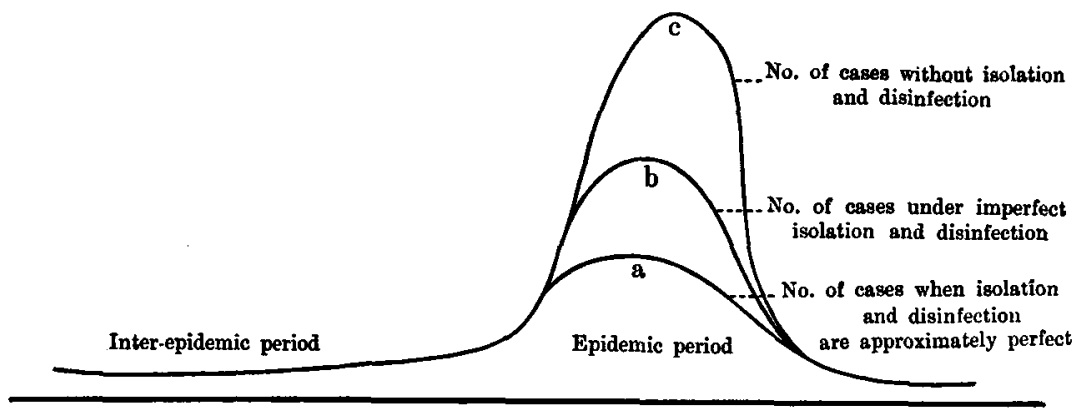

Fig. 2.

I have elsewhere compared the work of the hygienist to that of the staff of a fire-brigade, and the following remarks respecting diphtheria are equally applicable to scarlet fever. "To assume that because we do not yet know how to exterminate diphtheria, or because we cannot hope in our day to be entirely successful in preventing its spread, it is therefore useless to attempt anything, would be as unwise as it would be for a City Council to dismiss their fire-brigade staff and dispose of their fire-preventing apparatus, because the staff had not been successful in at once extinguishing every fire, or because the City Council were impressed with the fact that the present appliances for extinguishing fire are of a very imperfect character."

Until better means or supplementary means, the result of fuller knowledge of the natural history of scarlet fever, are devised, it is our obvious duty to persevere with the best known means of preventing the spread of this disease. The determination to persevere on these lines should be strengthened by our present knowledge of the disease. Although the micro-organism causing scarlet fever has not certainly been isolated, we know that the contagium of this disease, like that of other infectious diseases, is particulate; that it can be destroyed by disinfection, and that its dissemination can be prevented by isolation of the sick. It would therefore constitute a sin against knowledge to abstain from preventive action in these directions.

Referring to Fig. 2, the distance between $b$ and $c$ will obviously increase as preventive measures become more complete, until $a$ and $b$ coincide in position. We may consider, in conclusion, the reasons which have prevented hitherto, the attainment in any known district, of this ideal condition of things.

1 The origin and spread of Pandemic Diphtheria, 1898, p. 192. 
In the first place, hospital and home isolation have never been completely carried out. In very few districts does the percentage of cases removed to isolation hospitals exceed 80 : and general experience shows that the isolation of a large proportion of the remaining 20 per cent. is very imperfect.

Secondly, not only have a considerable proportion of notified cases remained un-isolated, but a considerable proportion of the total cases have not been notified; owing to various causes, such as failure to call in medical aid in slight and unrecognised cases, errors of diagnosis, and occasionally neglect to notify. It may be said, then, that notification has been a failure. It is however obviously preferable to have a system of notification in which say 80 per cent. of the total cases of scarlet fever are notified, rather than a total absence of notification, in which information (and the action that can be taken thereon) must necessarily be still more inadequate. Every additional case notified gives an additional opportunity for preventing the spread of the disease by personal infection; and every such notified case can be made a centre of inquiry leading to the detection of unnotified cases, if sanitary administration be active and intelligent.

Thirdly, the best sanitary administration cannot accomplish everything. There must be hearty cooperation on the part of parents and medical practitioners, if efforts to secure early diagnosis and early isolation are to be successful. At this point failure freqnently occurs. Cases are notified after being watched for several days, with the natural result that secondary and tertiary cases are common in the same household. The law is much more regardful of the welfare of cattle than of human beings. A doctor need not notify a case of scarlet fever until "he becomes aware" that it is certainly of this nature; a farmer must notify each case and each suspected case of foot and mouth disease. A parent need not call in a doctor for every suspected case; and if he does not, he can rarely be proved to have wilfully failed to inform the medical officer of health of an infectious case, as the proof involves the assumption that he or she possesses medical knowledge; and in the absence of such proof the parent cannot be punished for keeping the case secret. This may be said to be an argument against notification: it is rather an argument for improving its machinery. Imperfect information must be better than no information.

The consideration of the relative results obtained by hospital and home treatment of scarlet fever would take us too far afield. My own experience is that hospital-treated bave a lower case-fatality than home- 
treated cases, notwithstanding the fact that the former include a larger proportion of severe cases than the latter. The occurrence of " return cases" in connection with patients discharged from isolation hospitals is on a relatively small scale. Even though they could not be reduced below the present number, they would not detract to any great extent from the valuable work done by isolation hospitals. That they can be reduced in number by more rigid separation of acute from convalescent, and of uncomplicated from complicated cases is fairly certain.

The preceding remarks may be summarised as follows: scarlet fever being an infectious disease, personal contact between healthy and sick must be prevented, if its spread is to be abated. This can only be done, in connection with the majority of homes, by removal to an isolation hospital. The contagium being particulate and microbic can be destroyed by appropriate disinfection. So far as we know at present isolation and disinfection are the only practicable means for preventing or at least minimising its spread. These measures have not in the past been completely successful, because diagnosis has been defective, carelessness has been prevalent, and isolation has been delayed, and carried out in an insufficient number of cases; and because disinfection has often been effected in a perfunctory manner. Even were all these measures successfully carried out, there would probably remain a residuum of cases, occurring in cyclical waves.

To suppose that the spread of a disease caused by particulate infective material is not diminished by isolation of infective persons and by destruction of infective particles, and to suppose further that the occasional occurrence of "return cases" is more than a small drawback to the good achieved by isolation hospitals, is to strain the facts, and to arrive at a conclusion which is contradicted by our general knowledge of the causation of specific febrile diseases. 


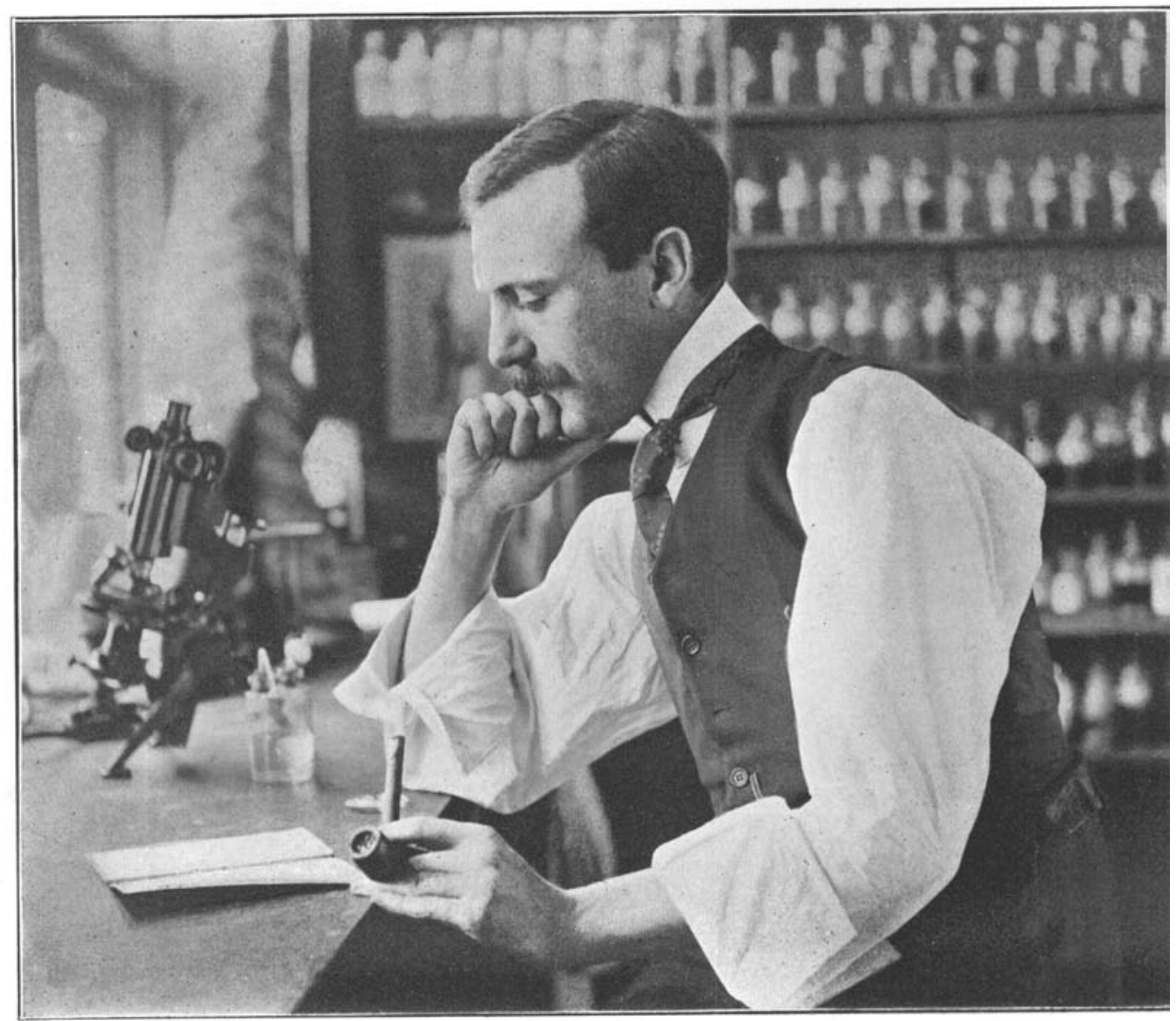

WALTER MYERS

Born at Birmingham, 28 March, 1872.

Died at Pará, Brazil, 20 January, Igor. 